\title{
Development of simplified models to assess pavement structural condition on network level
}

\author{
M. Pettinari \& S. Baltzer \\ Pavement section at the Danish Road Directorate, Hedehusene, Denmark \\ M. Kalantari \& D. Jansen \\ Section Design and Structure of Pavements at BASt, Bergisch Gladbach, Germany
}

\begin{abstract}
Monitoring pavement structural condition on network level has become possible since Traffic Speed Deflectometer (TSD) was introduced. TSD data have been deeply investigated over the past years and many studies have shown relatively strong correlation with Falling Weight Deflectometer (FWD) results. Furthermore, the agreed vison, formulated by road authorities and research institutions, is represented by utilizing the TSD data directly for back-calculation of the modulus of the pavement layers. To accomplish this vision, layer thicknesses and temperature of the asphalt layer must be available. While the second can be calculated by the help of BELLS (BALTZER, ERTMAN-LARSEN, LUKANEN and STUBSTAD) or similar models, layer thicknesses are not always available on network level. Based on this aspect, the Danish Road Directorate (DRD) and the German Federal Highway Research Institute (BASt) have been working on a project with the aim to develop simplified models that could rank the remaining lifetime of a pavement structure using Surface Curvature Index (SCI) data. This paper presents the models developed by using two approaches based i) on historical FWD data processed with a standard back-calculation software and ii) on simulated FWD loads, applied on different standard pavement sections analyzed with a multilayer linear elastic (MLE) based computer program. Comparing the results obtained by the two approaches, a power type function which correlates SCI and remaining life (in ESALs) was found where its coefficients are different from country to country. Effects of relevant variables such as damage development rate of the asphaltic layer and the effect of different countries fatigue transfer functions have also been considered.
\end{abstract}

Keywords: structural evaluation, TSD, network, FWD, pavement durability

\section{INTRODUCTION}

Billions of euros are spent by road agencies each year on managing the transportation infrastructure assets to comply regulations and user expectations. A major component of those assets is represented by pavements and their structural rehabilitation is becoming critical due to costs and complexity. To optimize maintenance strategies and decision on this manner, pavement management system (PMS) plays a fundamental role. An optimal indicator of the pavement structural condition is given by deflection measurements (Rada et al., 2016).

Measuring deflections is standard practice in pavement engineering and nowadays it can be performed at traffic speed. The Traffic Speed Deflectometer (TSD) is the most used version of moving deflection testing devices but their data have not been implemented yet to assess the 
pavement remaining lifetime. To calculate the lifetime of a pavement structure and its respective layers moduli, it is standard practice of road state agencies to still use back-calculation on Falling Weight Deflectometer (FWD) data (Lytton, 1988). FWD is a non-destructive testing (NDT) and non-intrusive device but, being stationary, becomes inefficient for network level application. Measuring with FWD is time demanding, due to the stop-and-go operation, and traffic disruptive. For this reason, many road authorities have been focusing on monitoring their network using structural data collected at traffic speed. So far, interpretation of these data for pavement management is based, in most of the cases, on the Surface Curvature Index 300 (SCI300) which is directly derived from the measured deflection basin as difference between specific peaks ( $\mathrm{d} 0$ and $\mathrm{d} 300$ ) at certain distances from the applied load (Levenberg et al., 2018; COST 336 - FWD at Network Level, 1998).

Recently, the TSD has also been implemented with three additional lasers behind the loading wheel with the intent to capture the asymmetry of the deflection basin produced by a moving load on a non-linear multilayer system. Furthermore, technological development has made the data collected by this vehicle repeatable and consistent opening to a new era for road authorities. In fact, the combination of the achievements in deflection measurements and the increased available computational power has made possible to use TSD data for backcalculation of the layer moduli and consequently the remaining ESALs (Nasimifar et al., 2017).

The implementation of this approach on project level and in the PMS is still not in place due to challenges faced: (i) accessing correct layers thickness and (ii) using asymmetric deflection basins generated by the TSD to assess remaining lifetime.

Layers' thicknesses reported in database system of road authorities are often not available at the required precision or not reliable. Consequently, thicknesses used for back-calculation of the layer moduli are conventionally taken by drilling cores or using the borescope. The ground penetrating radar (GPR) has become an alternative even if some processing limitations must be mitigated. With regards to the second point, layers moduli have been back calculated using TSD data but still some uncertainties are in place about the precision of calculated remaining equivalent single axle loads (ESALs) from stresses and strains obtained using a viscoelastic mechanistic model.

Based on these challenges, the Danish Road Directorate (DRD) and the German Federal Highway Research Institute (BASt) cooperated in a project with the objective of developing simplified models to classify the remaining lifetime of a pavement using Surface Curvature Index data. Since the developed models refers to FWD (both historical and simulated) analyzed with a multilayer linear elastic (MLE) theory and being aware that FWD and TSD loading configurations are different, these models are meant to be used only to ranking lifetime within different classes and additionally implemented in PMS to coordinate maintenance strategies.

\section{OBJECTIVE AND EXPERIMENTAL PROJECT DESCRIPTION}

This paper presents the primary results of a joint project between German Federal Highway Research Institute (will be referred as BASt) and Danish Road Directorate (will be referred as DRD), with the aim of developing a simple model to be able to assess the structural condition of the pavements on network level.

Among different methods of analyzing the data from FWD and TSD devices, deformationbased indexes are the most applicable parameters as they are easily calculated without needing extra parameters like the pavement layer's thicknesses. SCI 300 was selected for this research and correlated with residual life of the respective pavement. To determine the remaining life of the pavement, the mechanistic empirical (ME) method was applied in two different approaches:

I. Analysis of standard pavement sections: In this approach different standard pavement sections from Germany and Denmark were selected with material parameters as 
representative designs (named as model pavements). They were analyzed under the simulated FWD load to determine the surface deformations and the critical responses at desired points for calculation of the SCI and the remaining life of the sections.

II. Analysis of the existing FWD data: in this approach, the existing FWD measurements data (known as historical FWD data) were used to determine the SCI indexes and the backcalculation of layers' stiffnesses. The back calculated material characteristics were used in a ME method to determine the remaining life.

The results were used to develop models relating the SCI to the remaining life.

\subsection{Simulated FWD method}

A three-layer linear elastic model consisting of asphalt layer, granular layer and subgrade was selected to model the pavement sections subjected to FWD load of $50 \mathrm{kN}$ (with circular contact area of $15 \mathrm{~cm}$ radius). When needed, different asphaltic layers were combined in a single layer using Odemark method. BISAR ${ }^{\circledR}$ software was applied for the analysis of the model pavement sections. Fatigue cracking was considered as the failure criteria and therefore horizontal tensile strain at the bottom of the asphalt layer was taken as the critical response.

To select the German pavements, the national pavement design guideline known as RStO 12 (FGSV 499, 2012) was used. The guideline is a catalogue-based pavement design which propose different thicknesses based on the pavements traffic class and the type of its material in 7 different traffic classes (known as BK 100 to BK 0.3). For higher traffic amounts, the analytical design approach RDO Asphalt 09 should be used (FGSV 489, 2009).

To determine the stiffness of the asphalt layer for the model, the results of a research study performed in Germany were used (Stöckner et al., 2020). As a part of that study, a lot of asphalt data samples from wearing, binder and base layers were collected to determine typical stiffness master curves. The results, measured at $20^{\circ} \mathrm{C}$ and $10 \mathrm{~Hz}$, were classified in different levels and 5,000 MPa was selected as representative mean of the asphalt modulus for German pavement sections. Table 1 shows the properties of the German pavements model sections used in this study.

Table 1. Properties of the German pavements model sections.

\begin{tabular}{lllllll}
\hline & Thickness $(\mathrm{cm})$ & & & \multicolumn{3}{l}{ Stiffness/Modulus $(\mathrm{MPa})$} \\
Range & Asphalt layer & Granular layer & & Asphalt layer & Granular layer & Subgrade \\
\hline Min. & 14 & 30 & 50 & 5,000 & 200 & 90 \\
Max. & 34 & 30 & & 5,000 & 200 & 90 \\
\hline
\end{tabular}

To select the Danish side model pavements, the Danish design guidelines known as design catalogue and MMOPP guidelines (MMOPP Design Program for Road Pavements, 2017), were considered as the base.

In the design catalogue and in MMOPP, pavements are typically 4-layer structures (asphalt layer, gravel base layer, sand formation layer and subgrade), it was needed to transfer them into 3-layer structures by combining the two unbound layers. The modulus of the combined unbound layer was calculated as a weighted average. Table 2 shows the properties of the Danish pavements model sections. The stiffness of asphalt concrete was calculated from FWD measurements at the reference temperature of $20^{\circ} \mathrm{C}$. 
Table 2. Properties of the Danish pavements model sections.

\begin{tabular}{lllllll}
\hline & Thickness $(\mathrm{cm})$ & & & \multicolumn{3}{l}{ Stiffness/Modulus (MPa) } \\
\cline { 2 - 3 } Range & Asphalt layer & Granular layer & & Asphalt layer & Granular layer & Subgrade \\
\hline Min. & 13 & 47 & 2,230 & 180 & 40 \\
Max. & 31 & 91 & 4,280 & 220 & 40 \\
\hline
\end{tabular}

As mentioned before, fatigue was considered as the failure criteria and horizontal tensile strain at the bottom of the asphalt layer as the critical response. Fatigue damage was modeled by decreasing the stiffness of the asphalt material in 10\% steps. To relate the response to the life, DRD has their own fatigue transfer function (see equation 1) (MMOPP Design Program for Road Pavements, 2017).

$$
\varepsilon_{h}=-0.000250 \times\left(N 10 / 10^{6}\right)^{-0,191}
$$

Where $\mathrm{N}$ is allowable number of axles [ESAL of 10 ton] and

$\varepsilon_{h}$ is the largest permitted horizontal tensile strain under the asphalt layer. In Germany, for each RDO Asphalt pavement design, asphalt samples are tested in the laboratory under indirect tensile fatigue test (at $20^{\circ} \mathrm{C}$ and $10 \mathrm{~Hz}$ ) to determine the fatigue function of the relative asphalt material (see equation 2). This fatigue function is used with a shift and safety factor to determine the pavement's life in case of fatigue failure criteria (FGSV 489, 2009). In this research the proposed fatigue functions from the results of the before-mentioned research study (Stöckner et al. 2020), was used as the representative fatigue functions of the asphalt base materials in Germany. Table 3 represents the parameters of these fatigue functions. A factor of 1500 was used to shift the laboratory life to field life based on existing German analytical design guideline (FGSV 489, 2009).

$$
N=a \varepsilon^{b}
$$

where $\mathrm{N}$ is the number of load cycles till the initiation of the fatigue crack in the sample [-], $\varepsilon$ : Initial horizontal elastic strain [\%o]

a \& b: Fatigue parameters of the material which, are determined by the regression on the results of the fatigue tests

Table 3. Parameters of different classes of HMA base material's fatigue functions in Germany.

\begin{tabular}{lll}
\hline & \multicolumn{2}{l}{ Fatigue function parameters } \\
\cline { 2 - 3 } Different categories & $\mathrm{a}$ & $\mathrm{b}$ \\
\hline Upper class & 6.49415208 & -3.62690871 \\
Middle class & 4.92836355 & -3.21161007 \\
\hline
\end{tabular}

\subsection{Historical FWD method}

Historical FWD data were used to define a correlation between remaining lifetime of pavement structure and relative properties of the deflection basin. Since the overall objective of this study is to define a model that can be used with TSD data, deflection 
basin characteristics, such as SCI300 and SCI600, were used as independent variables of the regression analysis.

Table 4. Summary of the pavement structure characteristics used in the FWD analysis.

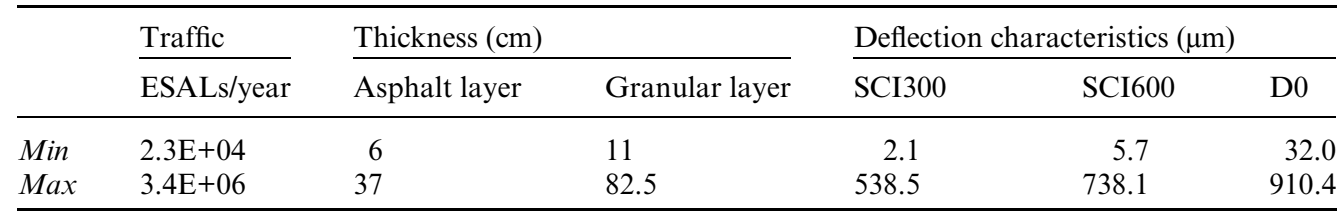

The sample of FWD data include approximately 700 measurements on pavement structure having a wide variety of bearing capacity levels. The table (Table 4) below includes some basic information about the deflection basins characteristics of the studied sample of data.

FWD measurements were carried out at different temperatures so all the back-calculated moduli of the asphalt layers were corrected to a reference temperature of $20^{\circ} \mathrm{C}$ and used to obtain the relative deflection basin. The following equation (equation 3 ) has been used to correct the asphalt modulus to the reference temperature of $20^{\circ} \mathrm{C}$.

$$
E_{20^{\circ} \mathrm{C}}=E(T) \times\left[1-2 \log 10\left(20^{\circ} \mathrm{C} / T\right)\right]
$$

where $\mathrm{E}(\mathrm{T})$ is the modulus of the asphalt layer at the temperature $\mathrm{T}$.

For each measurement, two different empirical approaches were used and compared: i) remaining lifetime is assessed using the empirical equations implemented in the Danish pavement design guide (MMOPP); ii) the lifetime is given by the back-calculation software ELMOD $^{\mathbb{R}}$. In both cases, all pavements were represented as three layers system and modeled using mechanistic model based on multilayer elastic theory (MLET). Three different failure points were evaluated based on: a) tensile strain at the bottom of the asphalt layer, b) stress on top of the granular layer and c) stress on top of the subgrade. Equation 1 is used to assess the durability of the asphalt layer while equation 4 is used to evaluate the potential failures based on the vertical stress for the failure points b) and c).

$$
\sigma=0.086 M P a \times\left(N / 10^{6}\right)^{-0,25} \times(E / 160 M P a)^{1.16}
$$

$\mathrm{N}$ is allowable number of ESALs of 10 ton

$\sigma$ is the vertical stress on top of the referring layer while $E$ is the relative modulus.

The remaining lifetime of the pavement was given by the lowest number of ESALs obtained by using the equation 1 , and 4 to the three critical points. ELMOD ${ }^{\mathbb{R}}$ estimates the remining lifetime using an incremental recursive method (IRME) where the material properties for the pavement are updated in terms of damage as the pavement life simulation progresses. This procedure works in increments of time and uses the output from one increment, recursively, as the input to the next increment. The IRME design method incorporates various mathematical models to describe and predict material and pavement performances.

\section{ANALYSIS OF THE RESULTS}

As described in the previous paragraph, all the models, used to assess the remaining lifetime of a pavement structure, have as input a physical stress or strain calculated trough a mechanistic model of the pavement structure subjected to a specific loading condition. To provide a better understanding of pavement structures included in this investigation, distribution of the critical tensile strains, used to calculate the remaining lifetime, are shown in 
Figure 1. For the sample of pavements of the historical FWD dataset, also vertical stresses on top of the granular base and subgrade are presented (Figure 2).

Considering the data processed using the simulated FWD method, almost $30 \%$ of the BASt structures included in this analysis have a peak of tensile strain at the bottom of the asphalt between 50 and $100 \mu$ strain. Still considering BASt structure, all intervals from 0-50 to 200250 are represented by at least $10 \%$ of the analyzed sections. The simulated DRD structures, since were selected trying to include a wide amount of traffic levels, show a wider distribution of tensile strains when compared to the BASt structures. In fact, the studied structures designed based on DRD guidelines are significantly represented also in the intervals 250-300 $\mu$ strain and 300-350 $\mu$ strain.

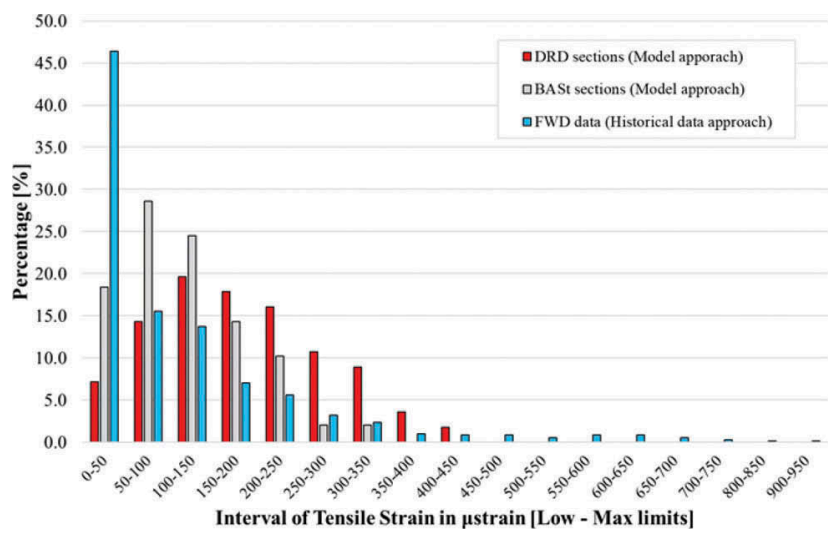

Figure 1. Summary of the horizontal tensile strains at the bottom of the asphalt layer investigated with both approaches.

Distribution of compressive stresses on top of granular layer and subgrade are represented in Figure 2. Calculated compressive stress applied on top of the granular layer reached a maximum value of approximately $0.6 \mathrm{MPa}$ while in the subgrade the maximum was $0.12 \mathrm{MPa}$.

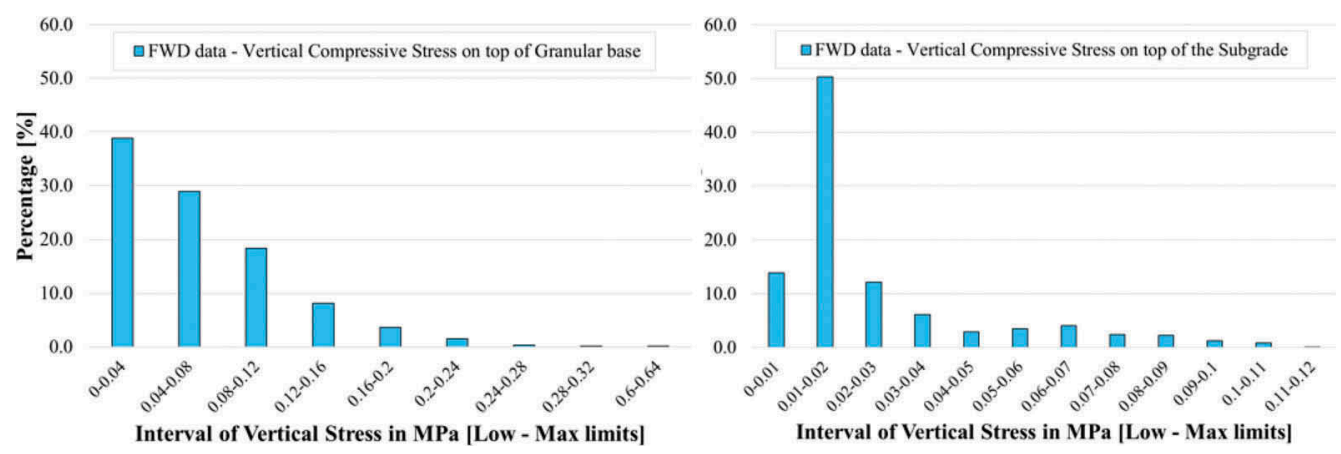

Figure 2. Stress distribution in investigated structures. Left. Stress on top of the granular layer, right. Stress on top of the Subgrade. 
Based on the presented strains and stresses given by the mechanistic model of the different pavement structures subjected to $50 \mathrm{kN}$ load applied on FWD plate, it was possible to develop several regression models where a surface deflection measure, such as SCI300, is used as input to define the remaining lifetime (Figure 3). It is important to select representative pavement and material properties in order to cover as many pavement types as possible.

Each dataset was used to define a reliable power regression model. While fitting the historical data back calculated using MMOPP and Dynatest Elmod ${ }^{\circledR}$, two additional models have been added. In both cases, a 3rd degree polynomial function was defined. To be conservative, both functions were shifted by a constant value towards the lower edge of the data. All the regression models have been summarized in Table 5. For all the models, $y$ represents the remaining number of 10-ton ESALs while $x$ is the SCI300 at the reference temperature of $20^{\circ} \mathrm{C}$
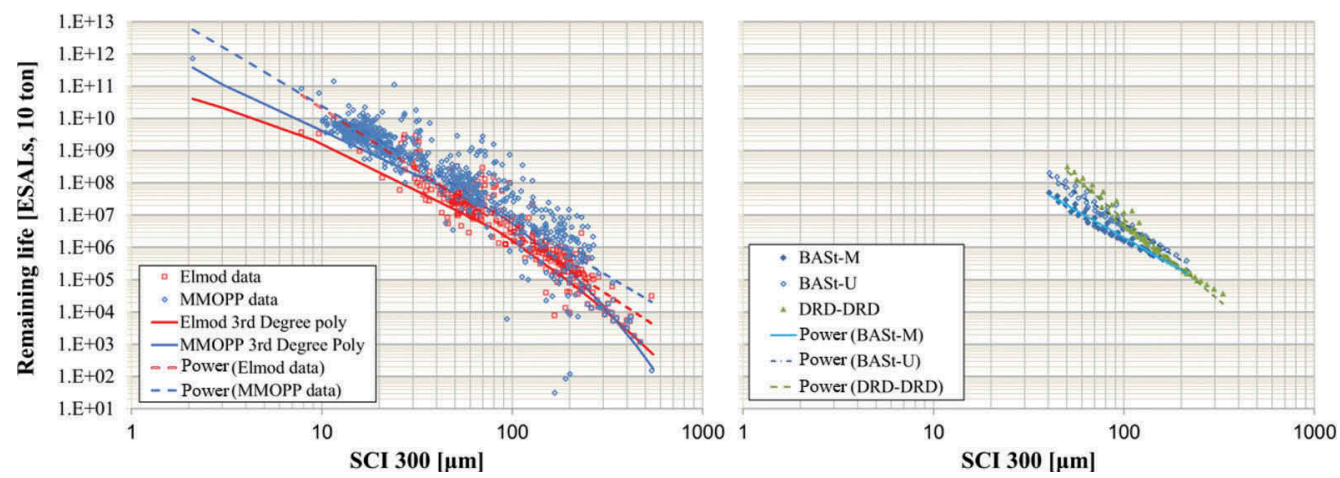

Figure 3. Left. Data and regression models using historical FWD data; right. Data and regression models using simulated FWD data.

Table 5. Summary of the regression models used to estimate remaining life.

\begin{tabular}{llllll}
\hline \multirow{2}{*}{ Name } & Model & Constants & $\mathrm{b}$ & $\mathrm{c}$ & $\mathrm{d}$ \\
\hline Pow. Elmod & Power & $1.45 \mathrm{E}+14$ & -3.8483 & $/$ & $/$ \\
Pow. MMOPP & Power & $7.72 \mathrm{E}+13$ & -3.504 & $/$ & $/$ \\
Pow. DRD & Power & $7.49 \mathrm{E}+16$ & -5.0056 & $/$ & $/$ \\
Pow. BASt U & Power & $1.86 \mathrm{E}+14$ & -3.7648 & $/$ & $/$ \\
Pow. BASt M & Power & $9.60 \mathrm{E}+12$ & -3.3395 & $/$ & $/$ \\
Poly Elmod & 3rd Poly & -0.1676 & -0.0221 & -1.7864 & $11.2^{*}$ \\
Poly MMOPP & 3rd Poly & -0.7519 & 2.4956 & -5.1178 & $13^{* *}$ \\
\hline
\end{tabular}

Description of the regression models

\begin{tabular}{lll}
\hline Model type & Power & 3rd Poly \\
\hline Function & $\mathrm{y}=\mathrm{a}^{*} \mathrm{x}^{\wedge \mathrm{b}}$ & $\mathrm{y}=\mathrm{a} * \log 10(\mathrm{x})^{3}+\mathrm{b}^{*} \log 10(\mathrm{x})^{2+} \mathrm{c}^{*} \log 10(\mathrm{x})+\mathrm{d}$ \\
\hline
\end{tabular}

*originally $11.577, * *$ originally 13.399

Even with the R-squared higher than 0.8 in all the studied cases, it is possible to foresee big challenges if residual life of a pavement should be assessed only based on SCI300. 


\section{COMPARISONS OF THE DIFFERENT METHODS/APPROACHES}

The overall objective of this research is to define a model that could be used to assess residual lifetime of a pavement structure using surface measurements of the deflection basins.

Comparing all the models (Figure 4) reveals how the difference between failure functions of two countries can influence the results. When considering the simulated FWD approach, it was important to use proper pavement structures and material properties because the criteria used in that case only refers to the strain at the bottom of the asphalt layer. Even if historical FWD approach is based on a failure criterion where all layers are evaluated, the overall comparison between the two approaches show consistent results. When considering SCI300 values between 40 and $200 \mu \mathrm{m}$, all the power regression models are consistent, independently from the approach used. The only exception is given by the DRD-DRD model when referring to SCI300 lower than $40 \mu \mathrm{m}$ where residual lifetime prediction seems much more optimistic than those given by the other models. The two polynomial models obtained using historical data, as specified in the previous paragraph, have been designed to be conservative and for this reason can be considered an exception.

Considering some specific SCI300 values within the above-mentioned range, the estimated remaining lifetime obtained from different regressions models are summarized in Table 6.

Table 6. Remaining pavement lifetime based on the different regression models.

\begin{tabular}{|c|c|c|c|c|c|c|c|}
\hline \multirow[b]{2}{*}{$\begin{array}{l}\mathrm{SCI} 300 \\
{[\mu \mathrm{m}]}\end{array}$} & \multicolumn{7}{|c|}{ Remaining Lifetime as number of 10-ton ESALs } \\
\hline & $\begin{array}{l}\text { Pow. } \\
\text { Elmod }\end{array}$ & $\begin{array}{l}\text { Pow. } \\
\text { MMOPP }\end{array}$ & $\begin{array}{l}\text { Pow. } \\
\text { DRD }\end{array}$ & $\begin{array}{l}\text { Pow. } \\
\text { BASt U }\end{array}$ & $\begin{array}{l}\text { Pow. } \\
\text { BASt M }\end{array}$ & $\begin{array}{l}\text { Poly } \\
\text { Elmod }\end{array}$ & $\begin{array}{l}\text { Poly } \\
\text { MMOPP }\end{array}$ \\
\hline 40 & $9.91 E+07$ & $1.88 \mathrm{E}+08$ & $7.16 \mathrm{E}+08$ & $1.73 \mathrm{E}+08$ & $4.29 \mathrm{E}+07$ & $3.91 E+07$ & $1.30 \mathrm{E}+08$ \\
\hline 60 & $2.08 \mathrm{E}+07$ & $4.54 \mathrm{E}+07$ & $9.41 E+07$ & $3.76 \mathrm{E}+07$ & $1.11 \mathrm{E}+07$ & $1.03 E+07$ & $3.66 \mathrm{E}+07$ \\
\hline 80 & $6.88 \mathrm{E}+06$ & $1.66 \mathrm{E}+07$ & $2.23 \mathrm{E}+07$ & $1.27 \mathrm{E}+07$ & $4.24 \mathrm{E}+06$ & $3.67 E+06$ & $1.31 \mathrm{E}+07$ \\
\hline
\end{tabular}

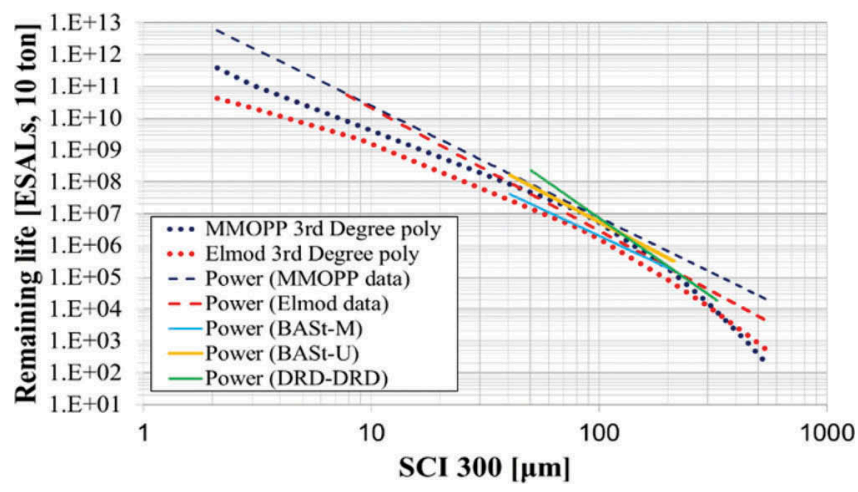

Figure 4. Comparing the results of the two approaches (historical FWD and simulated FWD).

As expected, maximum difference between predictions of the models increases with the increase in SCI. When SCI300 is equal to 80, the lowest prediction is 16 times smaller than that given by the Power DRD. 
When looking at the historical data it is also possible to see that, remaining pavement lifetime might vary up to 100 times compared to the value estimated using the regression model.

The overall outcome of the comparison between residual life from models and backcalculation highlights that it is not possible to precisely predict the remaining ESALs of a pavement structure just referring to SCI300. However, considering the different regressions it was possible to define ranges of expected durability for specific SCI300 values. To define these ranges, the following conditions have been followed:

- Power DRD model was not considered;

- Lower limit defined by the mean of the most conservative regressions

- Upper limit defined by the mean of the most optimistic regressions

- Mean values were rounded to the nearest $10^{6}$

Based on the mentioned points, the resulted residual life ranges for some SCI300 values are listed in Table 7.

Table 7. Defined thresholds for the relation of SCI

300 and remaining life.

\begin{tabular}{ll}
\hline SCI $300(\mu \mathrm{m})$ & Remaining life (ESAL of 10 ton) \\
\hline 40 & $40-180$ million \\
60 & $10-40$ million \\
80 & $4-15$ million \\
\hline
\end{tabular}

To narrow down the ranges of residual life for each SCI300, it is possible to apply a refining alternative approach based on different properties of the deflection basin. An example is given in Figure 5, where pavements having SCI300 between 0 and $30 \mu \mathrm{m}$ are shown. Based on this sample of pavements, the deflection property that better correlates with the residual lifetime is the difference between D600 and D900. When considering pavements with SCI300 between 30 and $60 \mu \mathrm{m}$, the deflection property that better predict pavement durability is the difference between D300 and D600.

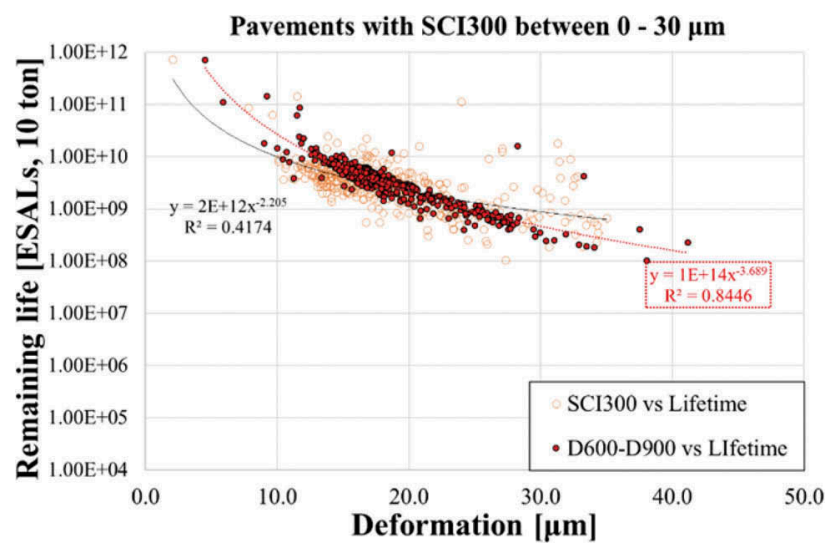

Figure 5. Alternative method for pavements having SCI300 at $20^{\circ} \mathrm{C}$ between 0 and $30 \mu \mathrm{m}$. 


\section{CONCLUSIONS}

Introduction of the TSD made a big change in pavement's structural condition monitoring activities. Back-calculation of the layers modulus from the measured data is still the common agreed method between most of the road authorities and institutes. Backcalculation requires the correct and precise thickness of the layers which, are not always existing or appropriate to measure on network level, considering the time and human resources. Therefore, developing simplified methods to estimate remaining life from the measured surface deformation parameters are welcomed by the road authorities to be able to integrate them in their pavement management systems. Considering this need, the Danish Road Directorate (DRD) and the German Federal Highway Research Institute (BASt) defined a joint research project. The primary results of this project were presented in this paper. Two different approaches were used to develop the models; by analyzing the simulated pavement sections under the FWD load and by back-calculation of the existing FWD data measured on different road sections. Different pavement sections and material properties were taken into account when selecting representative models of pavement structures. The distribution of the calculated tensile strains at the bottom of the asphalt layer in both approaches, showed a very good coverage of the different conditions in the real field. The results of both approaches were used to construct different models to relate the remaining life of the pavement with its SCI300. Excluding the most optimistic model ("Pow. DRD" model), there is good agreement between the simulated based and measured based models. Especially by comparing the "Pow. BASt U" as the optimistic simulated based with "Pow. MMOPP" as the optimistic measured based models. The same is by comparing the "Pow. BASt M" and the "Poly Elmod". Beside this agreement, comparing the predictions of the different models to the remaining lifetime assessed by FWD shows in many cases a significant difference. This highlights that it is not possible to precisely predict the remaining life of a pavement structure just referring to the SCI300 and there is a need for i) further improvement of the models by taking other surface parameters into account, ii) integrating a reliability approach into the assessment of the remaining life rages. The research will continue to address this issue but anyhow, the research so far has shown that it is possible to use the results to define thresholds for network level decision making activities.

\section{ACKNOWLEDGMENTS}

The authors gratefully acknowledge the Danish Road Directorate and Federal Highway Research Institute.

\section{REFERENCES}

FGSV 489. (2009). Richtlinien für die rechnerische Dimensionierung des Oberbaus von Verkehrsfächen mit Asphaltdeckschicht - RDO Asphalt.

FGSV 499. (2012). Richtlinien für die Standardisierung des Oberbaus von Verkehrsflächen, RStO 12.

Levenberg, E., Pettinari, M., Baltzer, S., \& Lekven Christensen, B. M. (2018). A Comparison of Traffic Speed Deflectometer and Falling Weight Deflectometer Data. Transportation Research Record: Journal of the Transportation Research Board, 2672(40), 22-31. https://doi.org/10.1177/0361198118768524

Lytton, R. (1988). Backcalculation of pavement layer properties. The First Symposim on Nondestructive Testing of Pavements and Backcalculation of Moduli, 55.

Nasimifar, B. M., Author, C., \& Pike, G. (2017). Backcalculation of Flexible Pavement Layer Moduli from Traffic Speed Deflectometer Data. Transportation Research Record: Journal of the Transportation Research Board, 2641(1), 66-74. https://doi.org/10.3141/2641-09 
Rada, G. R., Nazarian, S., Visintine, B. A., Siddharthan, R., \& Thyagarajan, S. (2016). Pavement Structural Evaluation at the Network Level: Final Report Number FHWA-HRT-15-074. September, 286p. https://doi.org/FHWA-HRT-15-074

Stöckner, Markus; Sagnol, Loba; Brzuska, Amina; Wellner, Frohmut; Blasl, Anita; Sommer, Viktoria; Krause, Günter; Komma, C. (2020). Abschätzung des Restwerts im PMS am Ende des Bewertungszeitraumes.

COST 336 - FWD at Network Level, (1998).

MMOPP design program for road pavements, (2017). 